\title{
Resonance Control Cooling System for the APT/LEDA CCDTL Hot Model
}

Federal Manufacturing \& Technologies

R. Floersch,

G. Domer, and

N. Jett

KCP-613-6178

Published April 1999

Approved for public release; distribution is unlimited.

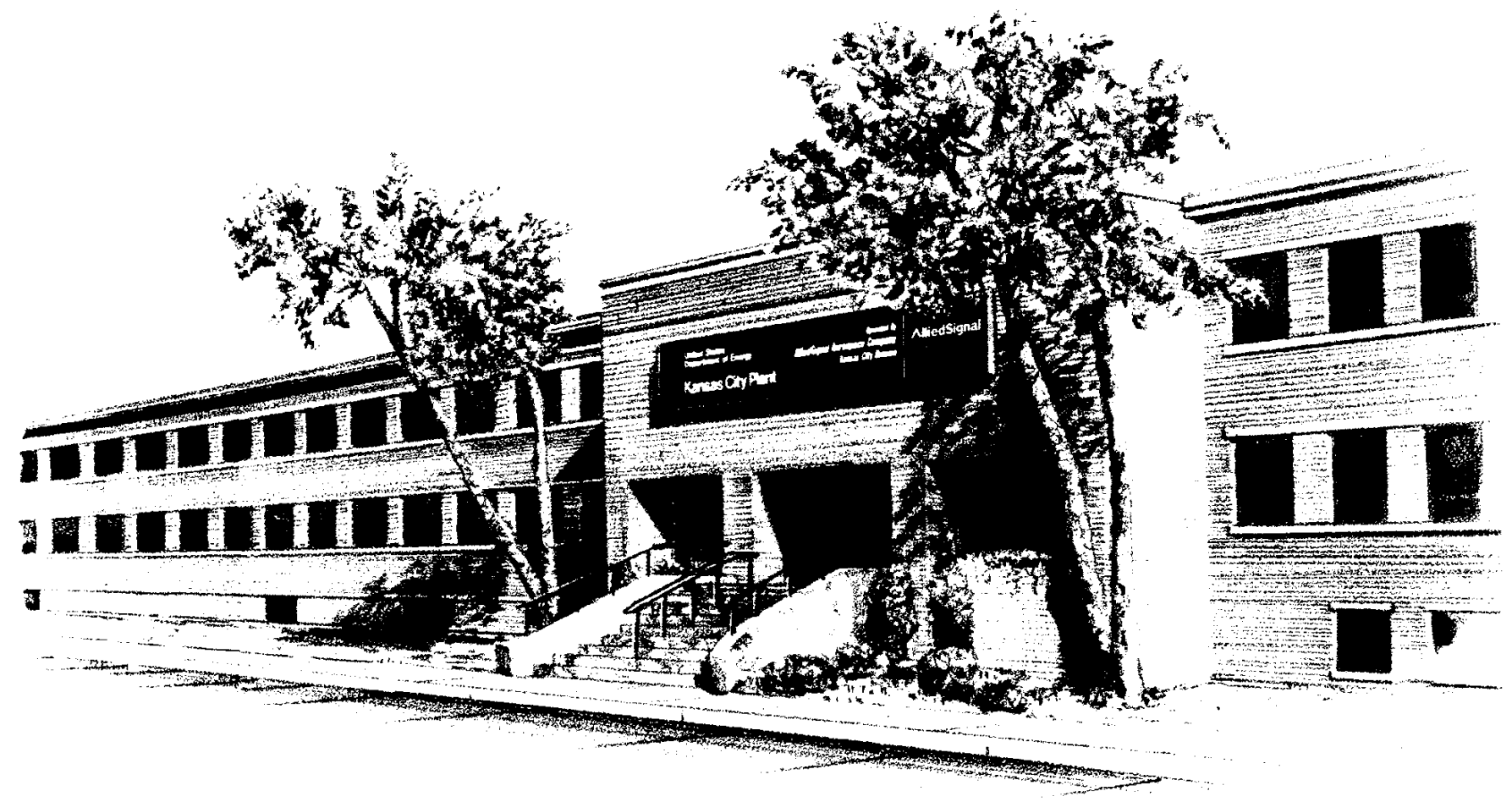




\title{
DISCLAIMER
}

This report was prepared as an account of work sponsored by an agency of the United States Government. Neither the United States Government nor any agency thereof, nor any of their employees, makes any warranty, express or implied, or assumes any legal liability or responsibility for the accuracy, completeness, or usefulness of any information, apparatus, product, or process disclosed, or represents that its use would not infringe privately owned rights. Reference herein to any specific commercial product, process, or service by trade names, trademark, manufacturer, or otherwise, does not necessarily constitute or imply its endorsement, recommendation, or favoring by the United States Government or any agency thereof. The views and opinions of authors expressed herein do not necessarily state or reflect those of the United States Government or any agency thereof.

Printed in the United States of America.

This report has been reproduced from the best available copy.

Available to DOE and DOE contractors from the Office of Scientific and Technical Information, P. O. Box 62, Oak Ridge, Tennessee 37831; prices available from (423) 576-8401, FTS 626-8401.

Available to the public from the National Technical Information Service, U. S. Department of Commerce, 5285 Port Royal Rd., Springfield, Virginia 22161, (703) 487-4650.

Copyright $\odot 1999$ by AlliedSignal Inc. The Government is granted for itself and others acting on its behalf a paid-up, nonexclusive, irrevocable worldwide license in this data to reproduce, prepare derivative works, and perform publicly and display publicly.

\author{
AlliedSignal Inc. \\ Federal Manufacturing \\ \& TorhnnInsise
}


A prime contractor with the United States

Department of Energy under Contract Number DE-ACO4-76-DP00613.
\& Technologies

P. O. Box 419159

Kansas City, Missouri

64141-6159 
KCP-613-6178

Distribution Category UC-706

Approved for public release; distribution is unlimited.

\title{
RESONANCE CONTROL COOLING SYSTEM FOR THE APT/LEDA CCDTL HOT MODEL
}

\author{
R. Floersch, \\ G. Domer, and \\ N. Jett
}

Published April 1999

Paper submitted to 1999 Particle Accelerator Conference March 28 - April 2, 1999

New York, New York 


\title{
RESONANCE CONTROL COOLING SYSTEM FOR THE APT/LEDA CCDTL HOT MODEL *
}

\author{
R. Floersch, G. Domer, N. Jett \\ AlliedSignal Federal Manufacturing \& Technologies**, Kansas City, Missouri 64141 USA
}

\section{Abstract}

The Hot Model for the Coupled Cavity Drift Tube Linac (CCDTL) resonance control cooling system (RCCS) for the Low Energy Demonstration Accelerator (LEDA) [] in support of the Accelerator Production of Tritium (APT) [2] is described. Two hydraulic control loops are described that control the frequency in the CCDTL Hot Model cavity. The two loops supply the required flow to the 32 channels. Control system schema is described to regulate resonant frequency during steady state operation.

\section{THE HOT MODEL}

The Hot Model was built to assess the design of the interface between single and dual gap cavities and is shown in Figure 1. Additionally, it will yield pressure drop and heat transfer information that will be useful for designing the LEDA CCDTL RCCS. The resonant frequency in the CCTDL Hot Model will be manipulated by independently changing the temperatures of the cavities and drift tubes to change their geometry which requires two hydraulic control loops.

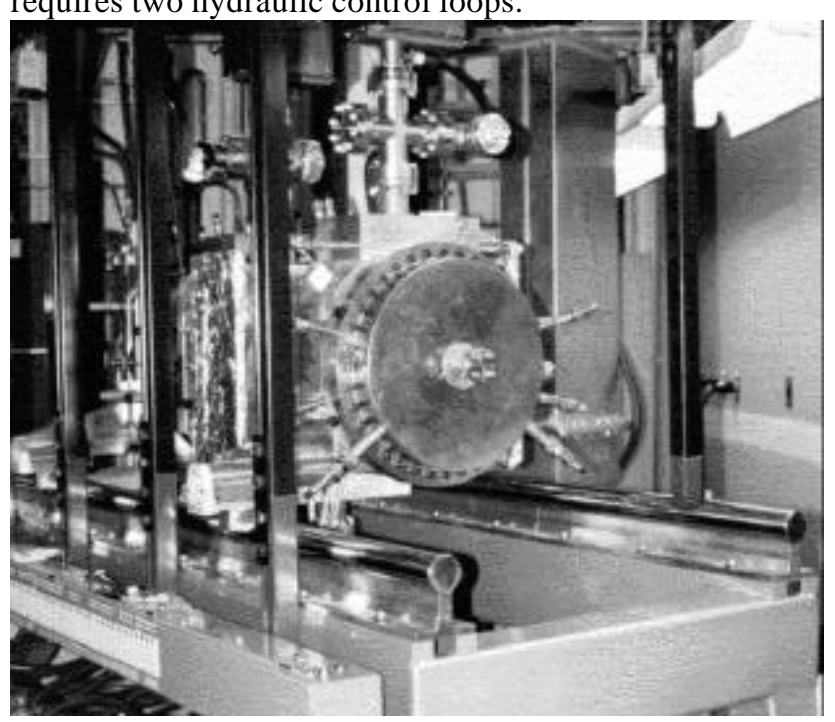

Figure 1 CCDTL Hot Model

\section{COOLING SYSTEM}

The resonance control cooling system is comprised of two independent hydraulic control loops, one drift tube and one end wall - equator.

\footnotetext{
* Work supported by the US Department of Energy.

** Operated for the US Department of Energy under Contract No. DE-ACO4-76-DP00613
}

\subsection{Drift Tube Loop}

The drift tube hydraulic control loop supplies controlled temperature coolant to the eight drift tube channel passages. Figure 2 illustrates the CCDTL Hot Model piping arrangement at the support stand. A total of 5.6 gallons per minute (GPM) of controlled temperature $60{ }^{\circ} \mathrm{F}$ water is required to dissipate approximately seven kilowatts of heat in these channels. The drift tube flows will be approximately 1 GPM in the single gap cavities and 0.6 GPM in the two gap cavities. Supply, return, and return bypass pipes distribute the controlled temperature water between the RCCS system (Figure 3) and the CCDTL Hot Model support stand (Figure 2).

Parallel piped flow metering valves are used to ensure the correct flow is supplied to each of the drift tube passages. Flow switches in each drift tube channel alarm when the flow drops too low.

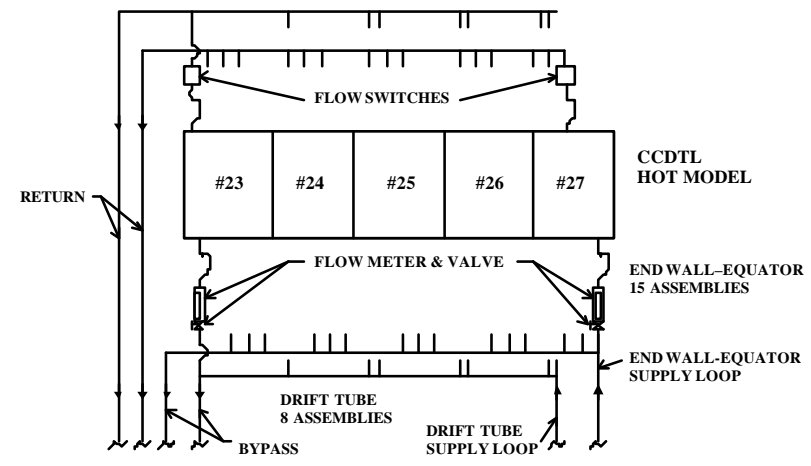

Figure 2 CCDTL Hot Model Piping Schematic

\subsection{End Wall - Equator Loop}

The end wall - equator loop is similar to the drift tube loop in that it supplies controlled temperature water to channel passages. A total of approximately $39 \mathrm{GPM}$ of $75^{\circ} \mathrm{F}$ controlled temperature water is required to dissipate approximately 29 kilowatts of heat in the channels. The flows in the 17 passages vary between 1.21 and 4.0 GPM among the end walls and equators.

Supply, return, and bypass piping; flow meters; and flow switches are similar to the drift tube loop.

\subsection{Hydraulic Control Loop}

Figure 3 illustrates the pump loop typical of both the drift tubes and end wall - equators. Each control loop uses a centrifugal pump to provide the driving energy. Pump flow is verified by flow meters in the suction piping of the pumping loop in combination with differential pressure 
across each pump. Each pump was sized to provide excess flow (above that required to provide cooling) to support heat transfer experiments and to access the impact of flow excess or starvation on resonant frequency. In addition, excess flow is necessary to achieve a $0.05{ }^{\circ} \mathrm{F}$ control sensitivity established as a design requirement.

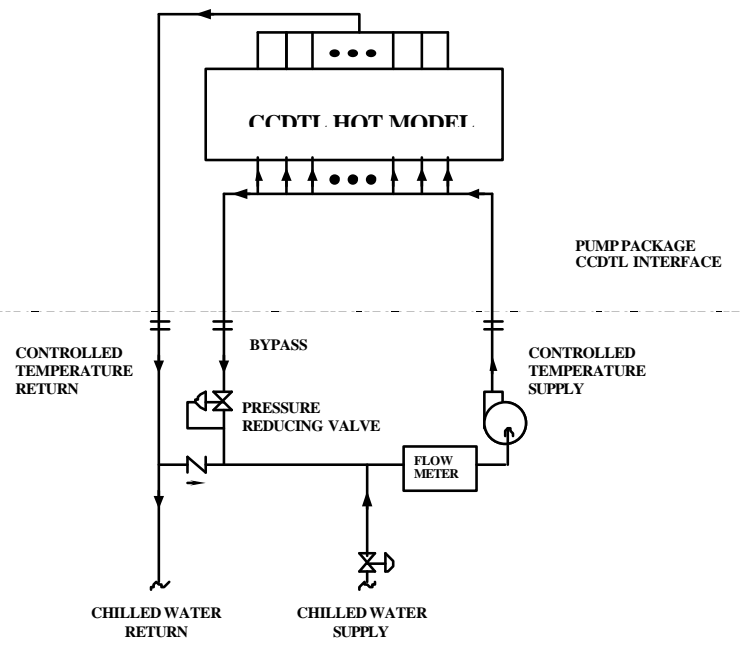

Figure 3 CCDTL Pump Loop - Typical

Pump flow is directed to a supply manifold where it is split to supply each of the drift tube channels. The excess flow passes through a pressure-reducing valve back to the pump suction. The pressure-reducing valve is set to match the resistance to flow through the drift tube channels. In the supply of each drift tube circuit, a flow indicator with metering valve is supplied to establish the desired flow. In the return of each drift tube circuit just prior to the return manifold is a flow switch to detect insufficient flow. The flow switches are monitored by the control system, which annunciates all flow alarms.

A pneumatic control valve effects control of the loop's temperature. The control valve allows a quantity of constant temperature $50{ }^{\circ} \mathrm{F}$ water from the chilled water system to mix with the heated returning water from the drift tubes. Since the control loop is constant mass, an equal amount of heated water is returned to the chilled water system. The quantity of chilled water entering the loop is a function of the control valve's stem position and the differential-pressure in the chilled water system's supply and return legs. The pneumatic valves were purchased with linear flow characteristics and were sized relative to the loop flow rate to achieve a $0.05{ }^{\circ} \mathrm{F}$ control sensitivity. Control sensitivity is defined as the change in loop temperature for the smallest change in valve stem position. A control algorithm (described in Section 3) manipulates the control valve.

Figure 4 shows the pump skid that houses the hydraulic control loops.

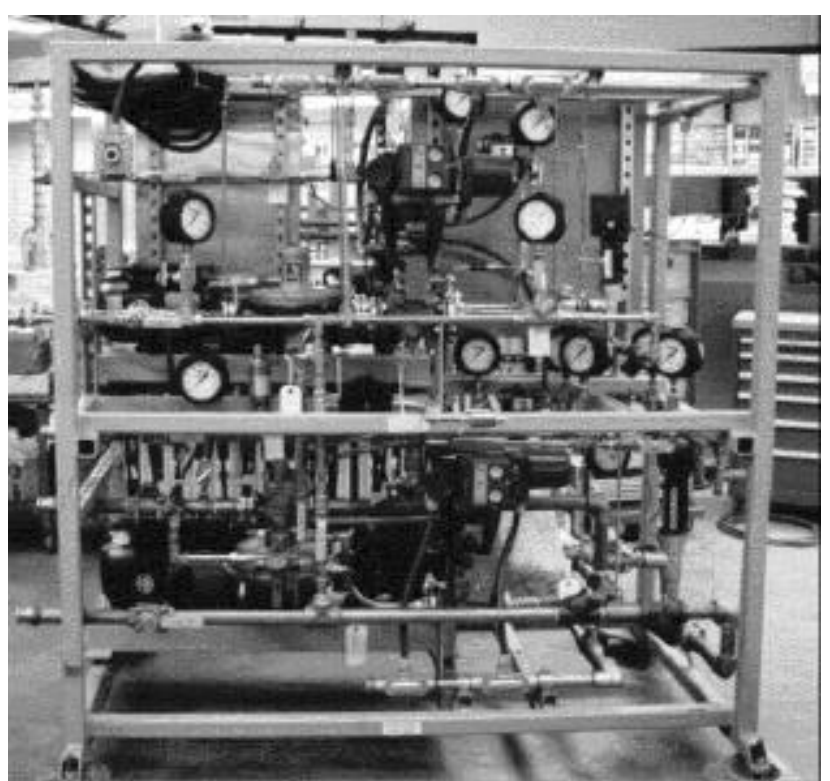

Figure 4 CCDTL Hot Model Pump Skid

\section{CCDTL CONTROL SYSTEM}

The CCDTL Hot Model RCCS provides continuous and discrete control of the cooling system. Operator interface screens are provided to change setup parameters for continuous control and to initiate discrete controls. Status screens are also provided to display information about the CCDTL Hot Model cooling system.

The RCCS is implemented using Experimental Physics and Control System (EPICS) based hardware and software. Figure 5 shows the network connections of the RCCS system.

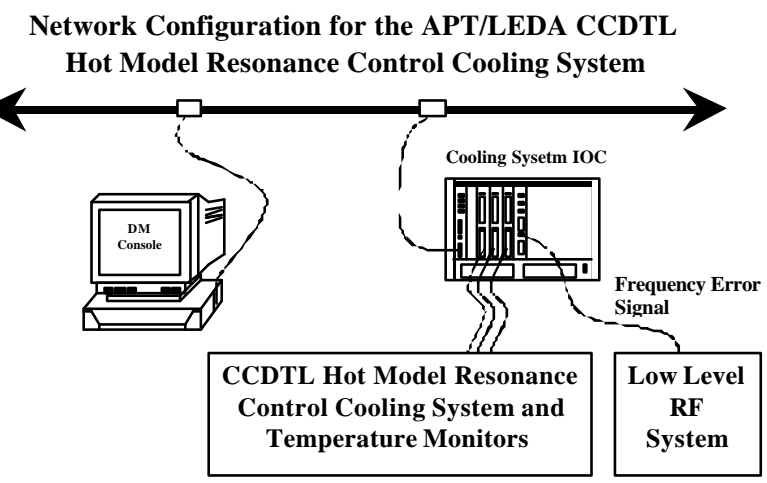

Figure 5 - Network Configuration

The RCCS software is constructed using EPICS State Notational Language (SNL) to track the condition of the system and to allow certain control actions to take place. Additional $\mathrm{C}$ functions contained in the SNL code are used to perform the control algorithms and file operations. Figure 6 shows the state diagram that represents the overall conditions of the RCCS.

The CCDTL Hot Model control system provides status screens that show temperatures of the water and cavities, 
vacuum levels in the cavities, activation of the channel flow switches, conditions of the PID loops, and conditions of the RCCS pumping systems. Screens are also provided to configure the PID algorithms and operate the RCCS components in an OVERRIDE mode.

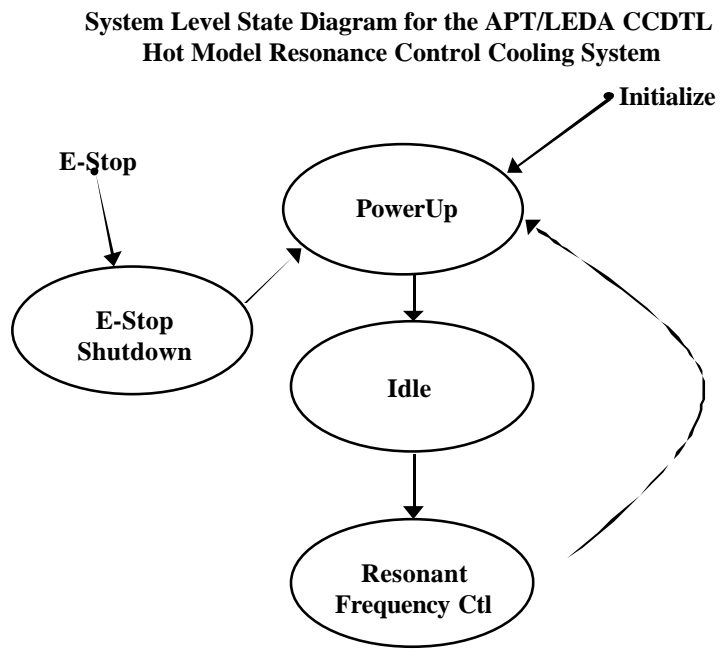

Figure 6 - System Level State Diagram

Resonant Frequency control (RFC) begins when the screen pushbutton pressed on the console system is detected and is the normal operating state of the RCCS. RFC regulates the resonant frequency of the CCDTL Hot Model using an independent single loop Proportional Integral Derivative (PID) control algorithm for each pump loop. The algorithms adjust the setting of the control valves based on the temperature of the water flowing to the Hot Model, the RF Power (calculated from the RF field signal), and the frequency error provided by the Low Level RF (LLRF) control system [3] (drift tube loop) or the change in length of the outer bodies (end wall - equator loop).

Figure 7 depicts the calculation of the error (e) supplied to the algorithms. From the figure, $\mathrm{e}_{\mathrm{p}}$ represents the frequency error for the drift tube loop and the body lengths in the end wall - equator loop; $x$ represents the RF field signal in the cavities. These 2 terms are combined to provide an adjustment to the temperature setpoint, $\mathrm{T}_{\mathrm{sp}} . \mathrm{T}_{\mathrm{ct}}$ is the temperature of the water supplied to the Hot Model at the discharge of each pump and is used to calculate the actual temperature error. The differential of $\mathrm{T}_{\mathrm{cw}}$ is used to anticipate the effects of a change in the chilled water temperature and apply it to the error. The error is supplied to the algorithm which makes valve adjustments that alter the temperature of the water flowing to the CCDTL Hot Model, thereby changing its frequency.

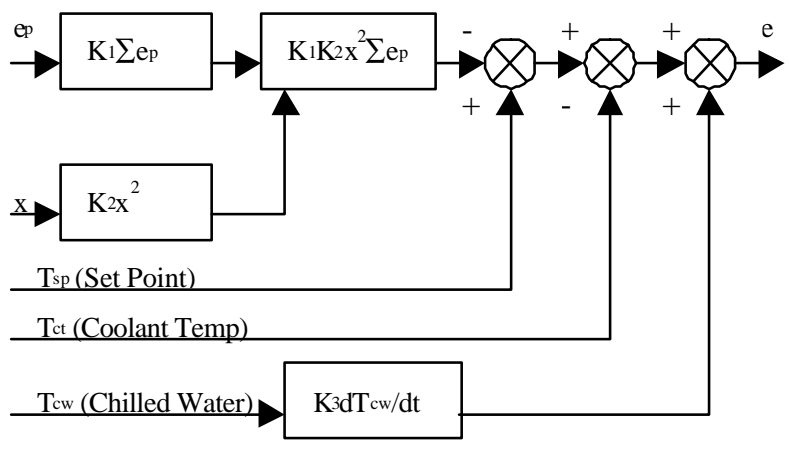

ep - frequency error (Drift Tube) or length error (EndWall-Equator)

$\mathrm{x}-\mathrm{RF}$ field signal $\quad \mathrm{e}-$ adjusted coolant error

Figure 7 - Control Loop Setpoint Adjustment Schematic

The frequency error received via an analog signal from the LLRF system, ranges from 0 to $10 \mathrm{~V}$ DC, where $+0.5 \mathrm{~V}$ represents $-50 \mathrm{KHz}$ error and $+9.5 \mathrm{~V}$ represents $+50 \mathrm{KHz}$ error. Any error reading outside the $+0.5 \mathrm{~V}$ to $+9.5 \mathrm{~V}$ range is considered an invalid signal.

The length measurements of the body will not be available for the CCDTL Hot Model. However, using the temperature readings of the bodies and a coefficient of expansion for the body materials we will be able to approximate the change in length.

RFC can only be halted and directed to make a transition to the proper state by the console system pushbuttons or an emergency stop condition.

The CCDTL Hot Model RCCS control system will be the basis for the design of the APT/LEDA CCDTL RCCS control system.

\section{INSTALLATION STATUS}

Installation of the RCCS CCDTL Hot Model and Cooling System Pump Package was completed in January 1999. Installation of the control system hardware and software was completed in February 1999. Final checkout and operation of the system will commence simultaneously with RF startup.

\section{ACKNOWLEDGEMENTS}

An immense amount of technical insight and installation assistance was provided by Rick Wood, Lloyd Young, and Paul Leslie, LANL.

\section{REFERENCES}

[1] H. V. Smith, "Status Update for the Low-Energy Demonstration Accelerator (LEDA)."

[2] G. Lawrence, "High Power Proton Linac for APT; Status of Design and Development."

[3] A. Regan, et al., "LEDA LLRF Control System Performance: Model vs Measurement;" these proceedings. 